\title{
Effect of Hydrogen on Amino-group Introduction onto the Polyethylene Surface by Surface-wave Plasma Chemical Modification
}

\author{
Martin Král $^{1}$, Akihisa Ogino ${ }^{2}$, Masaaki Nagatsu ${ }^{1,2}$ \\ ${ }^{1}$ Graduate School of Electronic Science and Technology, Shizuoka University, 3-5-1 \\ Johoku, Hamamatsu 432-8011, Japan \\ ${ }^{2}$ Graduate School of Science and Technology, Shizuoka University, 3-5-1 Johoku, \\ Hamamatsu 432-8561, Japan \\ E-mail: tmnagat@ipc.shizuoka.ac.jp
}

(Received

)

\begin{abstract}
:
This work reports the effect of hydrogen concentration on the amino group introduction by plasma treatment of the polyethylene surface. The amino group selectivity on polyethylene sheet treated by surface-wave plasma in various $\mathrm{N}_{2} / \mathrm{H}_{2}$ gas mixtures was examined by chemical derivatization combined with XPS. Amino derivatization along with X-ray photoelectron spectroscopy was employed in order to evaluate an amount of introduced amino group. Highest concentration of the amino group, about 2.0 in amino-N/100C-atoms, was obtained in the case of ammonia plasma treatment as well as the highest amino selectivity of about $100 \%$ in amino- $\mathrm{N} / \mathrm{N}$ ratio.
\end{abstract}

PACS numbers: 52.77.-j, 52.80.Pi, 82.33.Xj

Keywords: polymer surface modification, amino-group introduction, surface-wave plasma 


\section{Introduction}

Plasma treatment of polymers has drawn lot of attention especially for industrial and biological applications in the past decades. Change of the surface properties such as the wettability [1,2], adhesion [3,4], bacterial repellence[5] and others were performed using various plasma sources and arrangements. For the biological applications, it is often required to improve the biocompatibility by introducing the amino group $\left(\mathrm{NH}_{2}\right)$ onto a polymer surface [6-9]. Usually ammonia, nitrogen/hydrogen gas mixture and/or other gas admixture are used to create sufficient concentration of the $\mathrm{NH}_{2}$ on a polymer surface. Inagaki et al. studied the effect of process parameters by amino functionality introduction onto amorphous carbon sheet using the ammonia plasma[6]. With the amino derivatization technique, they estimated an introduced amino functionality to be at a level of 1.3-1.4 amino-N/100C-atoms. Similarly, Meyer-Plath et al. studied the influence of the process parameters by using the ammonia and nitrogen/hydrogen gas mixture $[7,8]$. Amino functionality introduction reached a value of about 2.8 amino-N/100 C-atoms by ammonia and ammonia-like nitrogen/hydrogen gas mixture. They obtained also a high amino selectivity of about $100 \%$ amino-N/N ratio by high hydrogen concentration (about $95 \%$ ). Wang et al. used nitrogen/hydrogen gas mixture plasma to treat the Polystyrene and examined surface free energy, degradation of the polymer, and amino functionality introduction[9].

In this study we focused on the amino group (functionality) introduction using 
microwave excited surface-wave plasma(SWP) in the nitrogen/hydrogen gas mixture and studied the influence of the hydrogen concentration and treatment time on the amino group introduction. The effect of hydrogen addition on the plasma parameters, such as electron temperatures, ion saturation currents and plasma potentials, has been studied using Langmuir probe measurement. To characterize the treated polyethylene(PE) surface, X-ray photoelectron spectroscopy (XPS) along with employing amino derivation technique has been carried out. The correlation between the hydrogen gas addition and the nitrogen-group introduction onto the polymer surface has been also discussed.

\section{Experimental setup}

The SWP device with a diameter of $40 \mathrm{~cm}$ and a height of $40 \mathrm{~cm}$ was used [10]. A schematic drawing of the experimental setup is shown in Fig. 1. Polyethylene (PE) sheet was used as obtained without further purification. Samples of $1 \times 2 \mathrm{~cm}^{2}$ in size were cut using stainless steel scissors and placed on the stage inside discharge chamber after cleaning by ethyl-alcohol. Microwaves of a frequency of $2.45 \mathrm{GHz}$ generated by magnetron of a maximum output power of $3 \mathrm{~kW}$ are coupled into the discharge chamber through a slot antenna cut in a rectangular waveguide. The slot antennas were placed onto a quartz plate located in an upper part of the discharge chamber. The introduced microwave power was typically $700 \mathrm{~W}$. This value was chosen not to be too high to affect samples thermally and 
also not to be too low to sustain stable plasma for reproducibility of the process. Samples were placed onto the sample holder at axial distance of $\mathrm{z}=11.5 \mathrm{~cm}$ to the quartz located at the top of the chamber. The $\mathrm{N}_{2}, \mathrm{H}_{2}$, and $\mathrm{NH}_{3}$ (purity of $99.99 \%$ ) gas were introduced to the discharge chamber using the mass flow controllers. The total gas flow was kept constant at a value of $100 \mathrm{sccm}$ and gas pressure was kept at a value of $13.3 \mathrm{~Pa}$. A N $\mathrm{N}_{2} / \mathrm{H}_{2}$ gas mixture ratio was varied from $0 \%$ to $75 \%$ in order to investigate the effect of hydrogen concentration on amino-group introduction. Results of $\mathrm{N}_{2} / \mathrm{H}_{2}$ plasma were compared to the results obtained using $\mathrm{NH}_{3}$ plasma.

To characterize the plasma, an electrical measurement using Langmuir probe was carried out. The probe made of tungsten wire having a diameter of $0.7 \mathrm{~mm}$ and a length of $3 \mathrm{~mm}$ was fixed at an axial position of $\mathrm{z}=11.5 \mathrm{~cm}$, which corresponds to the position of the samples during the plasma treatment. Current-voltage (I-V) characteristics were recorded using a PC and SCILAB program was used to calculate an electron temperature $T_{e}$ and a plasma potential $\mathrm{V}_{\mathrm{p}}$ of the plasma.

To characterize the plasma treated PE samples, XPS analysis was carried out using Shimadzu ESCA-3400 with a Mg anode $(1253.5 \mathrm{eV})$ operated at $200 \mathrm{~W}(10 \mathrm{kV}$ and $20 \mathrm{~mA})$ by pressure of $2 \times 10^{-6} \mathrm{~Pa}$. A photoelectron take-off angle was set to $90^{\circ}$ and pass energy was set to $75 \mathrm{eV}$. Spectra were calibrated with respect to the C 1s peak position $(285 \mathrm{eV})$ and decomposed using the curve-fitting program supplied by Shimadzu and SCILAB software 
using the least-squares method. The background shape of spectra was chosen to be linear and the fitting peaks were chosen to be combination of Gauss and Lorentz functions with a ratio of $80 \%$ Gaussian and $20 \%$ Lorentzian.

Chemical derivatization using 3-trifluoromethyl-benzaldehyde (TFB, $\mathrm{C}_{8} \mathrm{H}_{5} \mathrm{~F}_{3} \mathrm{O}$ ) of methanol solution $(0.1 \mathrm{M} / 15 \mathrm{ml})$ [6] was performed at a room temperature (about $22{ }^{\circ} \mathrm{C}$ ) for $12 \mathrm{~h}$ in order to estimate the introduced amino group concentration onto the PE surface. After the derivatization procedure, samples were rinsed for $10 \mathrm{~min}$ in the methanol followed by deionized water and dried under the vacuum at a room temperature. More details on derivatization can be found elsewhere [11]. Amino group concentration is then referred with respect to a carbon concentration in percents and denoted as amino-N/100 $\mathrm{C}$ or amino efficiency. Amino selectivity denoted as amino-N/N ratio gives information about selectivity of the process with respect to amino group.

\section{Results and discussion}

\subsection{Langmuir probe measurement}

The microwave excited planar surface-wave plasma is generally localized in the vicinity of the quartz and subsequently diffuses into the volume of the chamber. Hence, the plasma parameters as a plasma density, a plasma potential, and an ion saturation current decrease along the $\mathrm{z}$ axis with increasing distance from quartz surface. The plasma parameters were 
measured using the Langmuir probe fixed at $\mathrm{z}=11.5 \mathrm{~cm}$ when the $\mathrm{N}_{2} / \mathrm{H}_{2}$ gas mixture ratio was varied. Small amount of hydrogen added to the $\mathrm{N}_{2}$ plasma causes a steep decrease of the plasma potential $\mathrm{V}_{\mathrm{p}}$ from about $30 \mathrm{~V}$ in the case of the pure nitrogen plasma to about $22 \mathrm{~V}$ in the case of $5 \% \mathrm{H}_{2}$ addition $\left(\mathrm{N}_{2} / \mathrm{H}_{2}=95 / 5 \mathrm{sccm}\right)$. Further increase of the hydrogen concentration results in the decrease of the $\mathrm{V}_{\mathrm{p}}$ which in the case of the $75 \% \mathrm{H}_{2}\left(\mathrm{~N}_{2} / \mathrm{H}_{2}=\right.$ $25 / 75 \mathrm{sccm}$ ) reaches a value of about $13 \mathrm{~V}$. Tendency of the floating potential $\mathrm{V}_{\mathrm{f}}$ is similar to the $\mathrm{V}_{\mathrm{p}}$, which is a reason why the $\mathrm{V}_{\mathrm{p}}-\mathrm{V}_{\mathrm{f}}$ denoted as a $\Delta \mathrm{V}$ is very close to a constant value of about $4 \sim 6 \mathrm{~V}$, as shown in Fig. 2. Since the samples were placed on the insulating quartz plate of the substrate stage, ions are accelerated toward the sample by the potential difference of $\Delta \mathrm{V}=4 \sim 6 \mathrm{~V}$. Therefore, it is expected that ion bombardment onto the PE surface will evenly occur over the wide range of $\mathrm{N}_{2} / \mathrm{H}_{2}$ gas mixture in the present experiment.

Behavior of the $T_{e}$ is very similar to those of $V_{p}$ and $V_{f}$, as seen in Fig. 3. With an increase of hydrogen concentration, the $\mathrm{T}_{\mathrm{e}}$ decreases from about $1 \mathrm{eV}$ in the case of pure nitrogen plasma $\left(\mathrm{N}_{2} / \mathrm{H}_{2}=100 / 0 \mathrm{sccm}\right)$ to a value of $0.67 \mathrm{eV}$ in the case of $80 \% \mathrm{H}_{2}\left(\mathrm{~N}_{2} / \mathrm{H}_{2}=\right.$ 20/80 sccm). These relatively low values of $T_{e}$ are due to the position of the probe that is located in the downstream diffused plasma. Electron temperatures in both $\mathrm{NH}_{3}$ plasma and $\mathrm{N}_{2} / \mathrm{H}_{2}=25 / 75$ plasma are almost the same value of $0.7 \sim 0.75 \mathrm{eV}$. However, it is seen in Fig.2 that the value of $\mathrm{V}_{\mathrm{p}}$ in $\mathrm{NH}_{3}$ plasma of $29 \sim 30 \mathrm{~V}$ is about twice higher than the value of 13 14 $\mathrm{V}$ in $\mathrm{N}_{2} / \mathrm{H}_{2}=25 / 75$ plasma, and the value of $\Delta \mathrm{V}$ in the case of $\mathrm{NH}_{3}$ plasma $(8 \sim 10 \mathrm{~V})$ is also 
roughly twice higher than that in $\mathrm{N}_{2} / \mathrm{H}_{2}=25 / 75$ plasma(4 6 V). According to the simple probe theory with collisionless sheath, the ratio of $\Delta \mathrm{V}$ to Te is simply given by $|\Delta \mathrm{V}| / \mathrm{T}_{\mathrm{e}} \sim$ $\ln \left(M_{i} / 2 \pi m_{e}\right)$, where $M_{i}$ and $m_{e}$ are ion and electron masses, respectively[12]. Hence, a large difference in $\Delta \mathrm{V}$ might be originated from a difference of effective ion masses between $\mathrm{NH}_{3}$ and $\mathrm{N}_{2} / \mathrm{H}_{2}=25 / 75$ plasmas, under almost the same electron temperature. From comparison of ion saturation currents plotted in Fig. 3, we suppose that the effective ion mass in the $\mathrm{NH}_{3}$ plasma is larger than that in the $\mathrm{N}_{2} / \mathrm{H}_{2}=25 / 75$ plasma because of lower ion saturation currents in the $\mathrm{NH}_{3}$ plasma, under roughly the same electron densities in both the cases. This result is consistent with the observation of larger $\Delta \mathrm{V} / \mathrm{T}_{\mathrm{e}}$ in the case of $\mathrm{NH}_{3}$ plasma than in the $\mathrm{N}_{2} / \mathrm{H}_{2}=25 / 75$ plasma.

\subsection{X-ray photoelectron spectroscopy}

XPS spectra were analyzed for the atomic concentration change after the plasma treatment. In the survey spectra of the untreated PE samples, it is possible to distinguish two peaks attributed to $\mathrm{C} 1 \mathrm{~s}$ and $\mathrm{O} 1 \mathrm{~s}$, while peak $\mathrm{N} 1 \mathrm{~s}$ is not observed in the case of untreated PE sample. However, after the plasma treatment with the TFB derivatization technique, two additional peaks have appeared in $\mathrm{N} 1 \mathrm{~s}$ and $\mathrm{F} 1 \mathrm{~s}$. The $\mathrm{N}$ 1s peak suggests the nitrogen moieties introduced onto the PE surface by the plasma treatment and the F $1 \mathrm{~s}$ is originated from the TFB derivatization technique, which suggests the presence of the amino group on the 
PE surface. Decomposed spectra of the C 1s peak can be observed in Fig. 4. Untreated PE exhibits almost symmetrical peak that was decomposed into two components, that is, aliphatic C-C/C-H peaked at $285.0 \mathrm{eV}$ and C-O/C-N at $286.6 \mathrm{eV}$. The presence of the oxygen on the untreated PE surface is probably due to the oxides attached on the PE surface. This is probably due to the low binding energy of the $\mathrm{C}-\mathrm{H}$ and the UV radiation that can initiate oxidation of the surface by breaking specific bonds[13]. Decomposition of the plasma-treated samples spectra shows that there exists a relatively weak component with a peak at around $288.0 \mathrm{eV}$. This component might be attributed to the $\mathrm{C}=\mathrm{O}$ bond originated from the free bonds on the PE surface created by the plasma treatment. Increase of the $\mathrm{C}-\mathrm{O} / \mathrm{C}-\mathrm{N}$ component is due to the introduced nitrogen containing moieties and/or introduced oxygen after the ambient air exposure. Similarly the $\mathrm{C}=\mathrm{O}$ component is originated from the introduced oxygen after the treatment. As shown in Fig. 5, decomposition of the $\mathrm{N} 1 \mathrm{~s}$ spectra indicates that in the case of the ammonia plasma treatment the peak located at 399.2 eV can be attributed to amino group $\left(-\mathrm{NH}_{2}\right)$, whereas in the case of $\mathrm{N}_{2} / \mathrm{H}_{2}$ treated sample there can be recognized two peaks at a binding energies of $399.1 \mathrm{eV}$ assigned to amino group $\left(\mathrm{NH}_{2}\right)$ [14], and of $400.4 \mathrm{eV}$ that can be assigned to amide group $\left(\mathrm{O}=\mathrm{C}-\mathrm{NH}_{2}\right)[2,14]$. Comparing the ammonia plasma-treated sample and the $\mathrm{N}_{2} / \mathrm{H}_{2}$ plasma-treated one, we find higher intensity of the amide $\left(\mathrm{O}=\mathrm{C}-\mathrm{NH}_{2}\right)$ component in the case of the $\mathrm{N}_{2} / \mathrm{H}_{2}$ treated sample, what can be attributed to the higher amount of introduced nitrogen moieties, as seen in Fig. 6 . The 
highest value of $\mathrm{N} / \mathrm{C}$ ratio reached about $10 \%(\sim 10 \mathrm{~N} / 100 \mathrm{C}$ ratio $)$. The nitrogen and/or oxygen moieties are introduced mostly onto the sample surface and with increasing depth their concentration decreases, what is probably reason of low $\mathrm{N} / \mathrm{C}$ and $\mathrm{NH}_{2} / \mathrm{C}$ ratio.

\subsection{Amino group dependence on hydrogen concentration and treatment time}

The gas composition has also an effect on the amino group introduction process as seen in Fig. 6, where microwave power was $700 \mathrm{~W}$, pressure $13.3 \mathrm{~Pa}$, and treatment time $30 \mathrm{~s}$. The N/100 C ratio referring to the overall nitrogen groups introduction onto the polymer surface shows a sharp decrease from about $9.5 \mathrm{~N} / 100 \mathrm{C}$ in the case of $\mathrm{N}_{2}$ plasma $\left(\mathrm{N}_{2} / \mathrm{H}_{2}=\right.$ $100 / 0 \mathrm{sccm})$ to about $5 \mathrm{~N} / 100 \mathrm{C}$ when $\mathrm{H}_{2}$ gas was added by only $5 \%$ into the $\mathrm{N}_{2} / \mathrm{H}_{2}(=95 / 5$ sccm) plasma. Further an increase of the $\mathrm{H}_{2}$ concentration leads to the decrease of the N/100 $\mathrm{C}$ ratio that reaches a value of about $4 \mathrm{~N} / 100 \mathrm{C}$ in the case of $75 \%$ of $\mathrm{H}_{2}$. The observed decrease of the N/100 C ratio is simply understandable because nitrogen concentration itself decreased with an increase of hydrogen addition. The steep decrease of the N/100 C ratio by introducing of about $5 \%$ of $\mathrm{H}_{2}$ is caused by the effect of hydrogen etching of the $\mathrm{N}$-containing groups rather than the decrease of the $\mathrm{N}_{2}$ concentration, because further decrease in $\mathrm{N}_{2}$ concentration has not resulted in so strong reduction of the $\mathrm{N} / 100 \mathrm{C}$ ratio. As shown in Fig. 3, the ion saturation current peaked at roughly $5 \%$ hydrogen addition. This increase of electron density suggests the simultaneous increase of hydrogen radicals which 
will serve as the etchant of nitrogen-groups introduced on the PE surface. This might lead to the rapid decrease in nitrogen-group when a small amount of hydrogen was added. Introduction of the amino group behaves opposite way as the nitrogen does. The amino group concentration slightly increases with $\mathrm{H}_{2}$ concentration, as shown in Fig. 6. Amino group concentration in the $\mathrm{NH}_{3}$ plasma and $75 \% \mathrm{H}_{2}$ plasma show smaller difference compared to the concentration of the overall introduced nitrogen groups.

Dependence of the introduced nitrogen group on the $\mathrm{H}_{2}$ concentration as a function of the treatment time can be observed in Fig. 7. For various $\mathrm{H}_{2}$ concentrations, the time dependences of the $\mathrm{N} / 100 \mathrm{C}$ ratio are very similar, i.e. after reaching the local maximum the ratio slightly decreases. The treatment time required to reach the local maximum varies from the $30 \mathrm{~s}$ treatment time in the case of $10 \% \mathrm{H}_{2}$ plasma to $15 \mathrm{~s}$ in all other measured cases. The temporal evolution of the $\mathrm{N} / 100 \mathrm{C}$ ratio is determined from the balance between the generation by nitrogen-related group addition and the loss by hydrogen etching on the PE surface. To discuss the detail of temporal behavior, we will need to analyze the neutral particle species during the plasma process. We are now preparing the experiment using the quadrupole mass spectrometer to study the radicals and ions. These results will be presented and discussed in the future work.

The time dependences of nitrogen-group and amino group show relatively similar variation in value with treatment time, as shown in Fig. 7 and Fig. 8. The nitrogen group 
addition occurs very rapidly after the on-set of the plasma, then slightly decreases in time. Combining the amino group/100 $\mathrm{C}$ ratio and $\mathrm{N} / 100 \mathrm{C}$ ratio, one is able to obtain the amino selectivity dependence on the experimental conditions, as shown in Fig. 9. It can be clearly observed that $\mathrm{NH}_{3}$ plasma is more selective in the amino group introduction than $\mathrm{N}_{2} / \mathrm{H}_{2}$ plasma does. This means there is mostly amino group introduced onto the PE surface during the $\mathrm{NH}_{3}$ plasma treatment. The selectivity reaches values in range from $60 \%$ to $100 \%$. Comparing to results obtained by Meyer-Plath [7,8], we have obtained the $100 \%$ selectivity applying relatively long time ( $30 \mathrm{~s}$ comparing to $0.2 \mathrm{~s}$ applied in the mentioned papers). They also observed very similar results for introduced amino group concentration for $\mathrm{NH}_{3}$ and $\mathrm{N}_{2} / \mathrm{H}_{2}$ plasma treatment. Our results show that $\mathrm{NH}_{3}$ plasma is more effective from a point of view of the amino group introduction and the amino selectivity.

\section{Conclusion}

In this work the effect of hydrogen concentration on the amino group introduction was studied. The plasma potential and electron temperature were investigated with increasing of hydrogen concentration in $\mathrm{N}_{2} / \mathrm{H}_{2}$ gas mixture plasma. With a small amount of hydrogen addition, significant decreases in plasma potential and electron temperature were observed. This strongly correlated with the steep decrease in nitrogen-group introduction, N/100 C. Ammonia plasma exhibited the electron temperature of $0.75 \mathrm{eV}$ at a level of ammonia-like 
$\mathrm{N}_{2} / \mathrm{H}_{2}$ gas mixture but plasma potential of $30 \mathrm{~V}$ was roughly equal to that in the case of $\mathrm{N}_{2}$ plasma. Amino group introduction was more efficient in the case of ammonia plasma as well as amino group selectivity. Highest concentration of the amino group, about 2.0 in amino-N/100C-atoms, was obtained soon after the onset of ammonia plasma (treatment time $>5 \mathrm{~s})$. The highest value of about $100 \%$ in amino- $\mathrm{N} / \mathrm{N}$ ratio was obtained after $30 \mathrm{~s}$ ammonia plasma treatment.

\section{Acknowledgements}

This work has been partly supported by Grant-in-Aid for Scientific Research from Japan Society for the Promotion of Science (JSPS). 


\section{References}

[1] Svorcik V, Kotal V, Slepicka P, Blahova O, Spirkova M, Sajdl P and Hnatowicz V 2006 Modification of surface properties of high and low density polyethylene by Ar plasma discharge Polym. Degrad. Stab. 91 1219-25.

[2] Bryjak M, Gancarz I, Pozniak G and Tylus W 2002 Modification of polysulfone membranes 4. Ammonia plasma treatment Eur. Polym. J. 38 717-26.

[3] Friedrich J F, Mix R and Kuhn G 2005 Adhesion of metals to plasma-induced functional groups at polymer surfaces Surf. Coat. Technol. 200 565-68.

[4] Arefi-Khonsari F, Kurdi J, Tatoulian M and Amouroux J 2001 On plasma processing of polymers and the stability of the surface properties for enhanced adhesion to metals Surf. Coat. Technol. 142-144 437-48

[5] Amanatides E, Mataras D, Katsikogianni M and Missirlis Y 2006 Plasma surface treatment of polyethylene terephthalate films for bacterial repellence Surf. Coat. Technol. $2006331-35$

[6] Inagaki N, Narushima K, Hashimoto H and Tamura K 2007 Implantation of amino functionality into amorphous carbon sheet surfaces by $\mathrm{NH}_{3}$ plasma Carbon 45 797-804

[7] Meyer-Plath A A, Finke B, Schröder K and Ohl A 2003 Pulsed and cw microwave plasma excitation for surface functionalization in nitrogen-containing gases Surf. Coat. Technol. 
[8] Meyer-Plath A A, Schröder K, Finke B and Ohl A 2003 Current trends in biomaterial surface functionalization -- nitrogen-containing plasma assisted processes with enhanced selectivity Vacuum $71391-406$

[9] Wang M, Chang Y and Poncin-Epaillard F 2003 Effect of the addition of hydrogen in the nitrogen cold plasma: The surface modification of polystyrene Langmuir 19 8325-30

[10] Kral M, Ogino A, Narushima K, Inagaki N, Yamashita M and Nagatsu M 2007 Low-Temperature Nitrogen Introduction onto Polyurethane Surface Using Surface-Wave Excited $\mathrm{N}_{2} / \mathrm{H}_{2}$ Plasma Jpn. J. Appl. Phys., Part 1146 7470-74

[11] Everhart D C and Reilley C N 1981 Chemical derivatization in electron spectroscopy for chemical analysis of surface functional groups introduced on low-density polyethylene film Anal. Chem. 53 665-76

[12] Lieberman M A and Lichtenberg A J, 1994 Principles of Plasma Discharges and Materials Processing, John Wiley \& Sons (New York), p175

[13] Massey S, Roy D and Adnot A 2003 Study of natural ageing of polypropylene by X-ray photoelectron spectroscopy Nucl. Instrum. Methods Phys. Res., Sect. B 208 236-41

[14] Narushima K, Yamashita N, Fukuoka M, Inagaki N, Isono Y and Islam M R 2007 Surface modification of polyester films by ammonia plasma, Jpn. J. Appl. Phys. 46 $4238-4245$ 


\section{Figure Captions}

Fig. 1. Schematic drawing of the device used for polyethylene plasma treatment.

Fig. 2. Plasma potential $V_{p}$, floating potential $V_{f}$, and subtraction $\Delta V=V_{p}-V_{f}$ dependence on the gas composition measured using Langmuir probe at a pressure of $13.3 \mathrm{~Pa}$, introduced microwave power of $700 \mathrm{~W}$ and at a distance of $11.5 \mathrm{~cm}$ from the quartz plate.

Fig. 3. Electron temperature $T_{e}$ and ion saturation current $I_{i s}$ dependence on the gas composition measured using the Langmuir probe. Ion saturation current was measured at $-50 \mathrm{~V}$. I-V characteristics were measured at a pressure of $13.3 \mathrm{~Pa}$, an introduced microwave power of $700 \mathrm{~W}$ and at a distance of $11.5 \mathrm{~cm}$ from the quartz plate.

Fig. 4. XPS spectra of $\mathrm{C} 1 \mathrm{~s}$ peak for untreated(top), $\mathrm{N}_{2} / \mathrm{H}_{2}=25 / 75$ plasma(middle) and ammonia plasma(bottom) treated PE samples.

Fig. 5. XPS spectra of $\mathrm{N} 1 \mathrm{~s}$ peak for untreated(top), $\mathrm{N}_{2} / \mathrm{H}_{2}=25 / 75$ plasma(middle) and ammonia plasma(bottom) treated PE samples. Process parameters: pressure 13.3 Pa, power $700 \mathrm{~W}$, and treatment time $30 \mathrm{~s}$.

Fig. 6. Dependence of overall $\mathrm{N}$ and amino- $\mathrm{N}\left(\mathrm{NH}_{2}\right)$ specimens on the hydrogen concentration. Dependence of the amino selectivity $\left(\mathrm{NH}_{2} / \mathrm{N}\right)$ is also plotted. Process parameters: pressure $13.3 \mathrm{~Pa}$, power $700 \mathrm{~W}$, and treatment time $30 \mathrm{~s}$. 
Fig. 7. Dependence of the introduced nitrogen on the treatment time for various gas mixtures.

Fig. 8. Dependence of amino group ratio on the treatment time for various gas mixtures.

Fig. 9. Dependence of amino selectivity on the treatment time for various gas mixtures. 


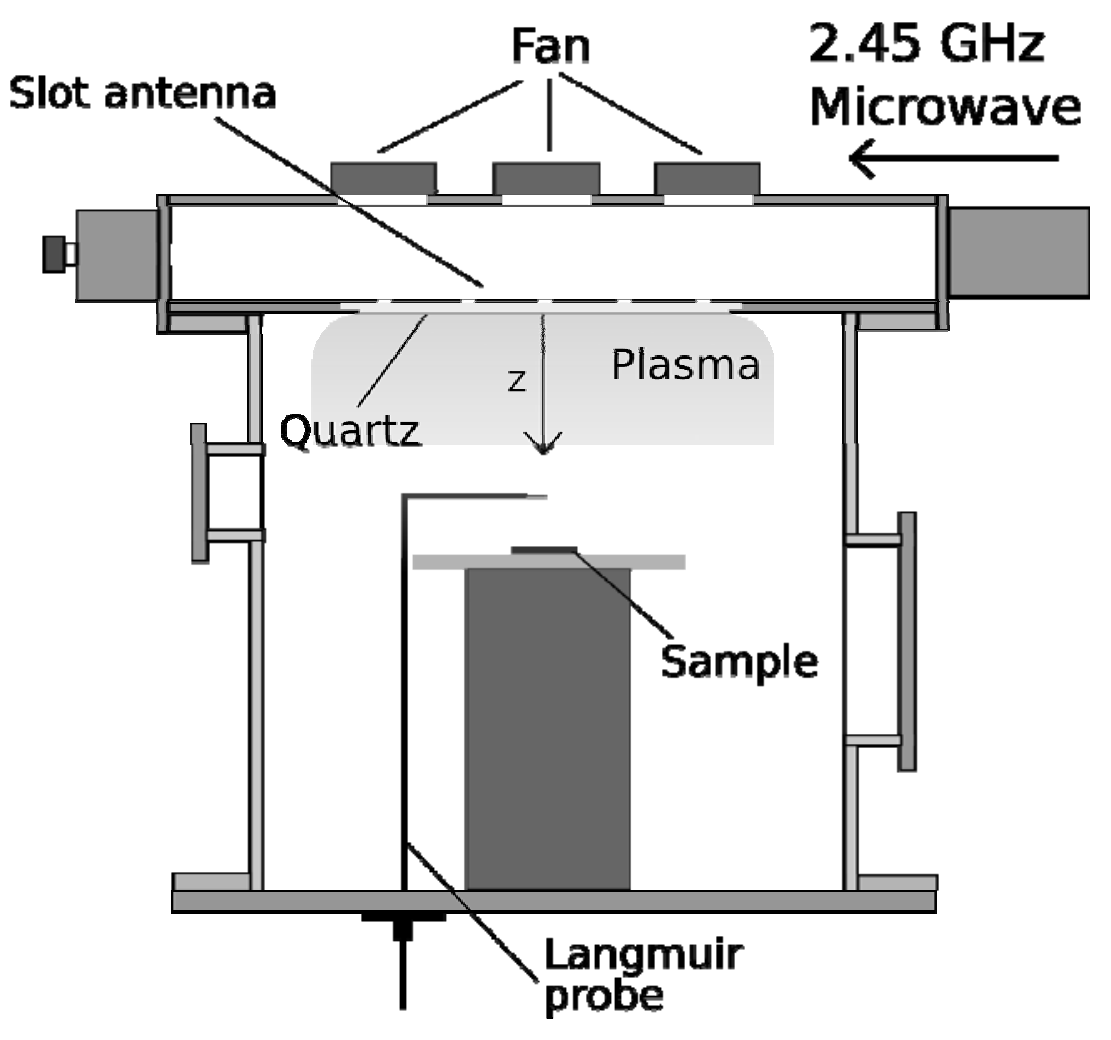

Figure 1. 


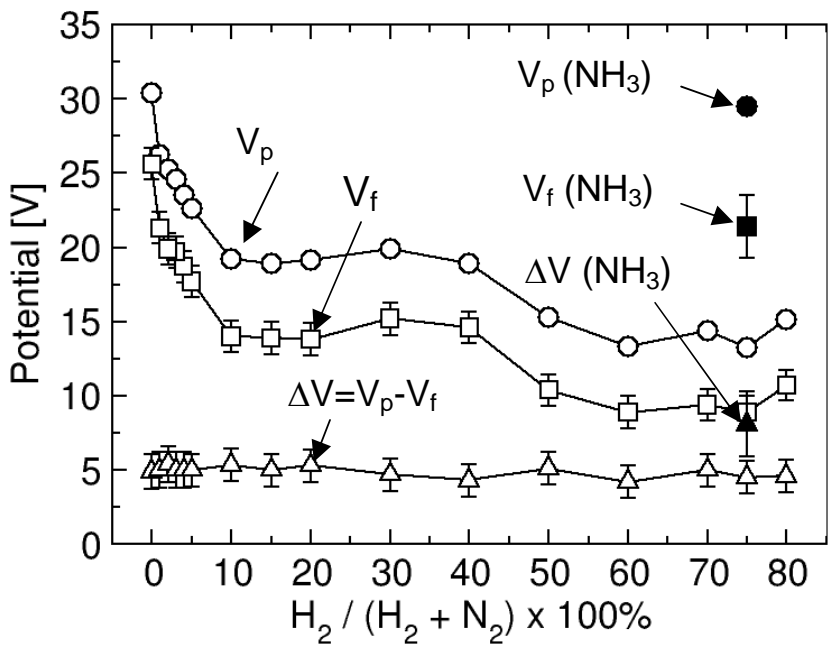

Figure 2. 


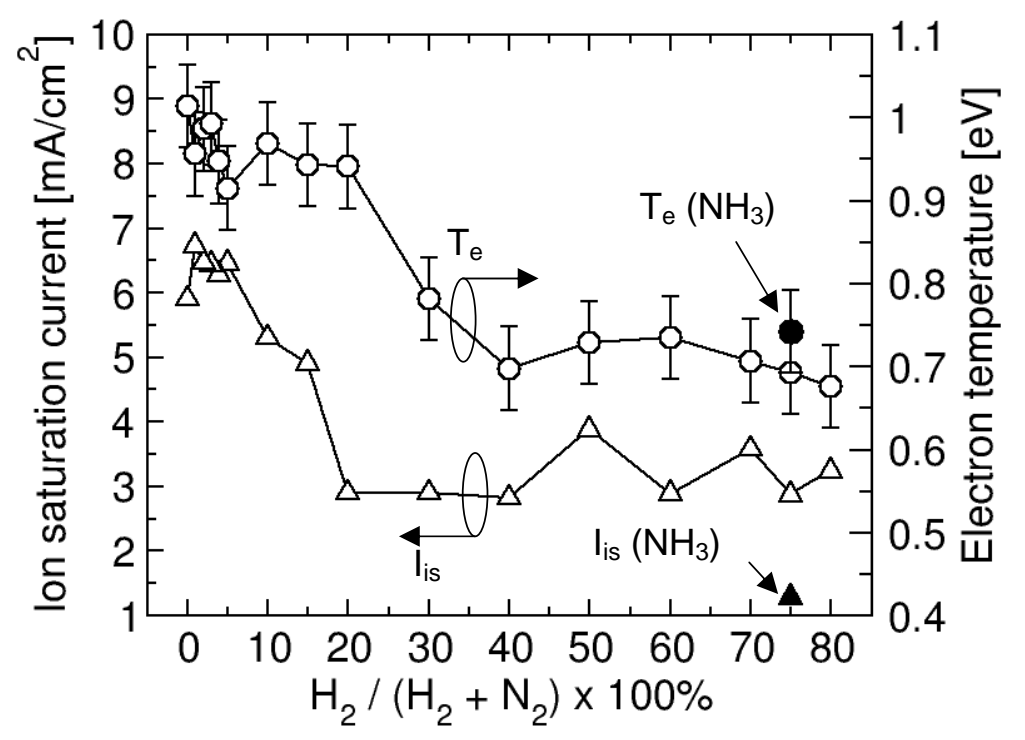

Figure 3. 


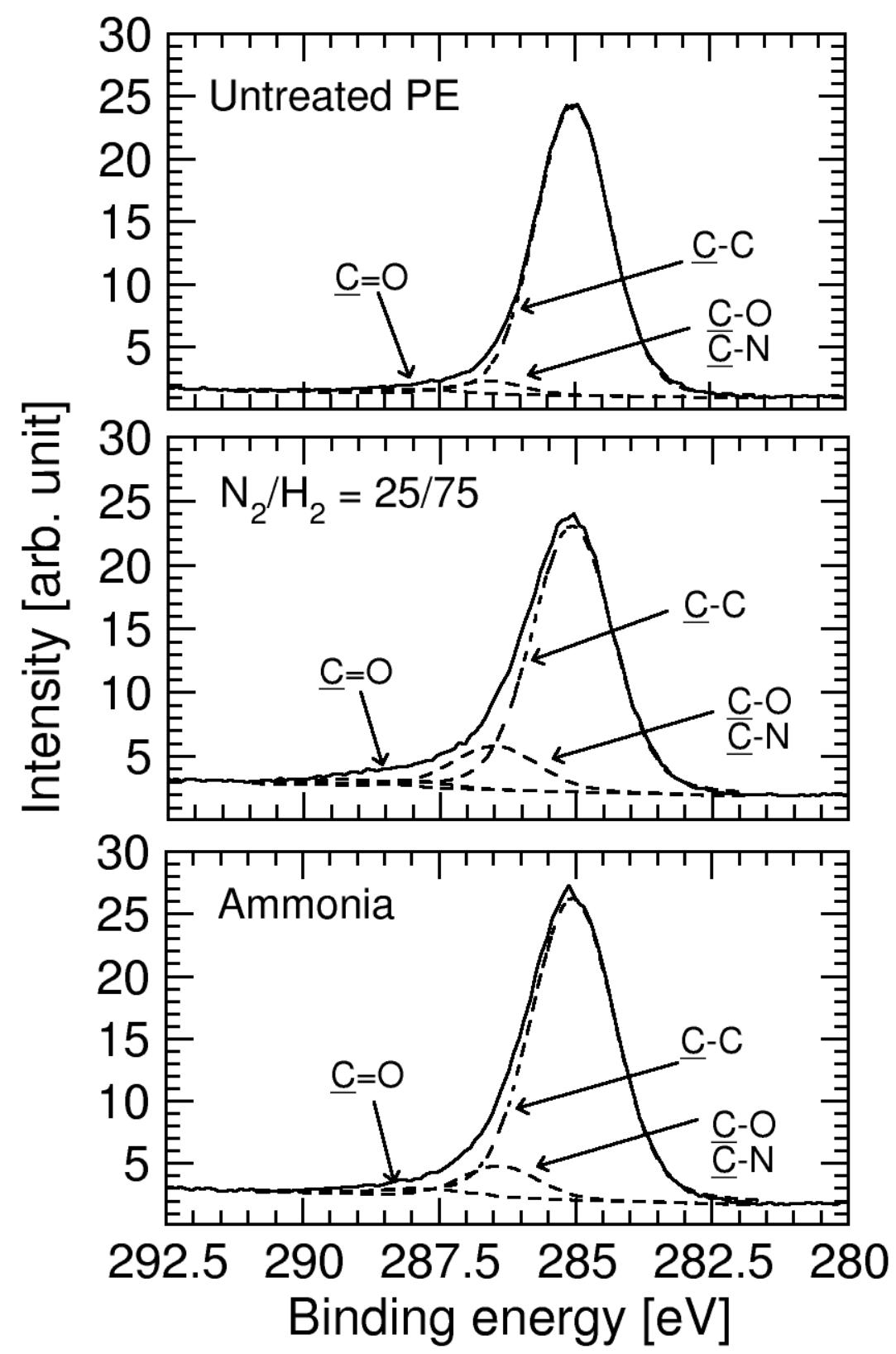

Figure 4. 


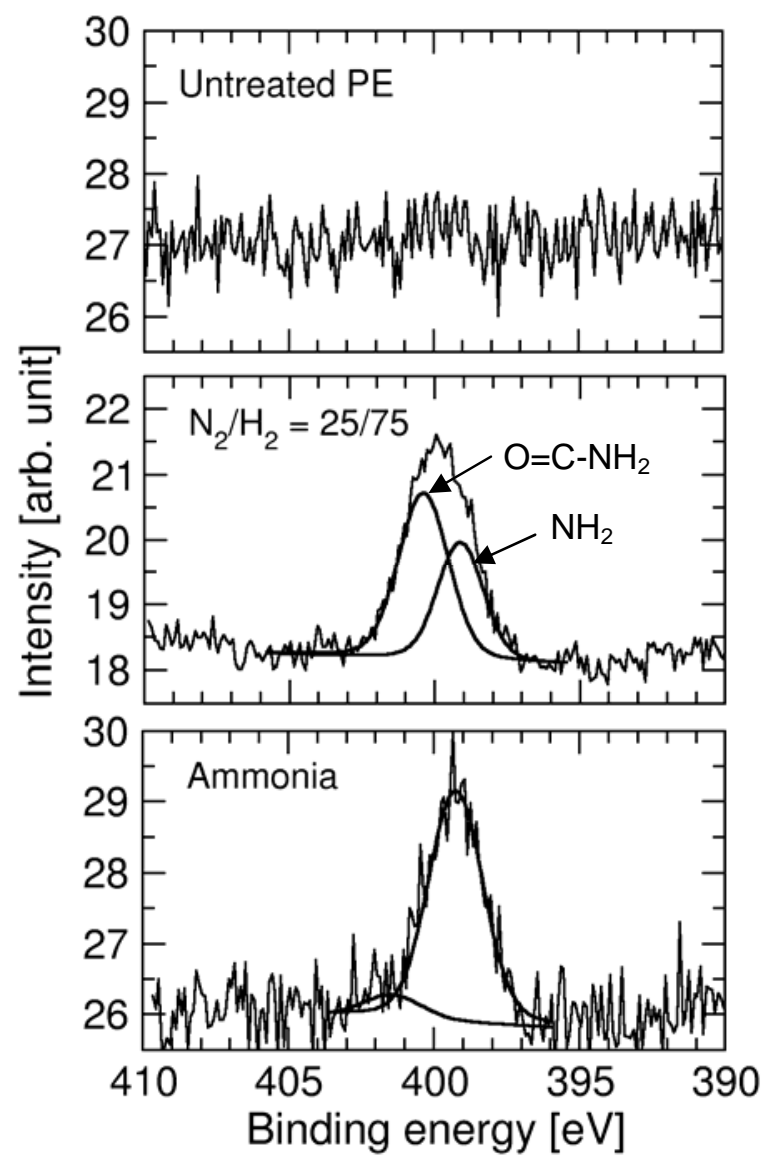

Figure 5. 


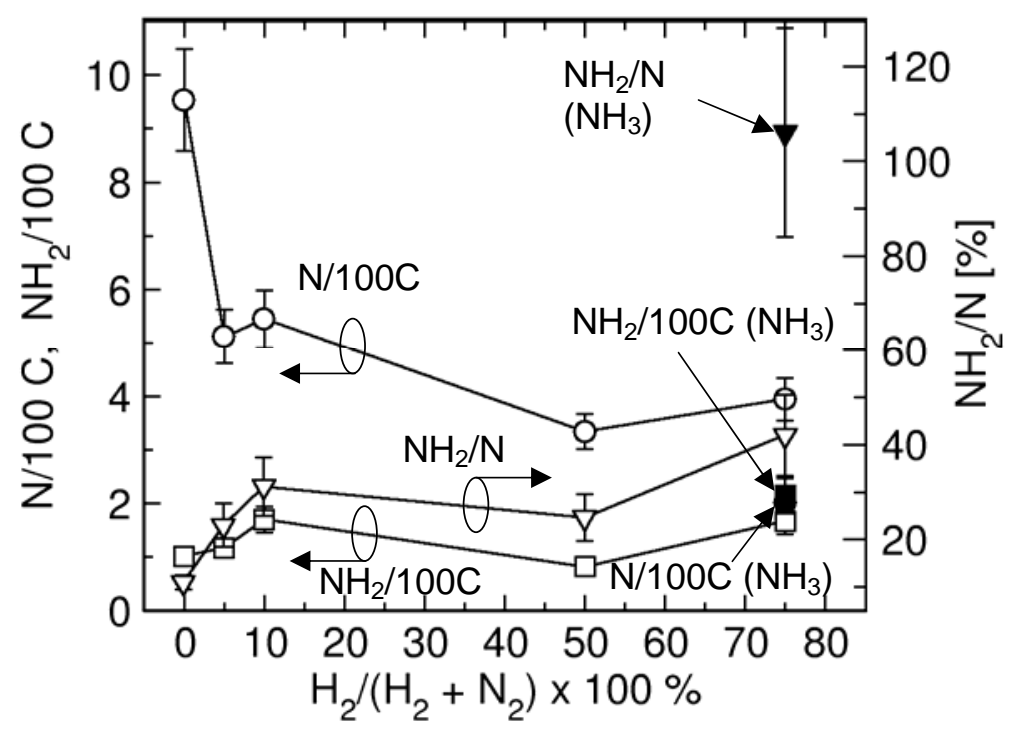

Figure 6. 


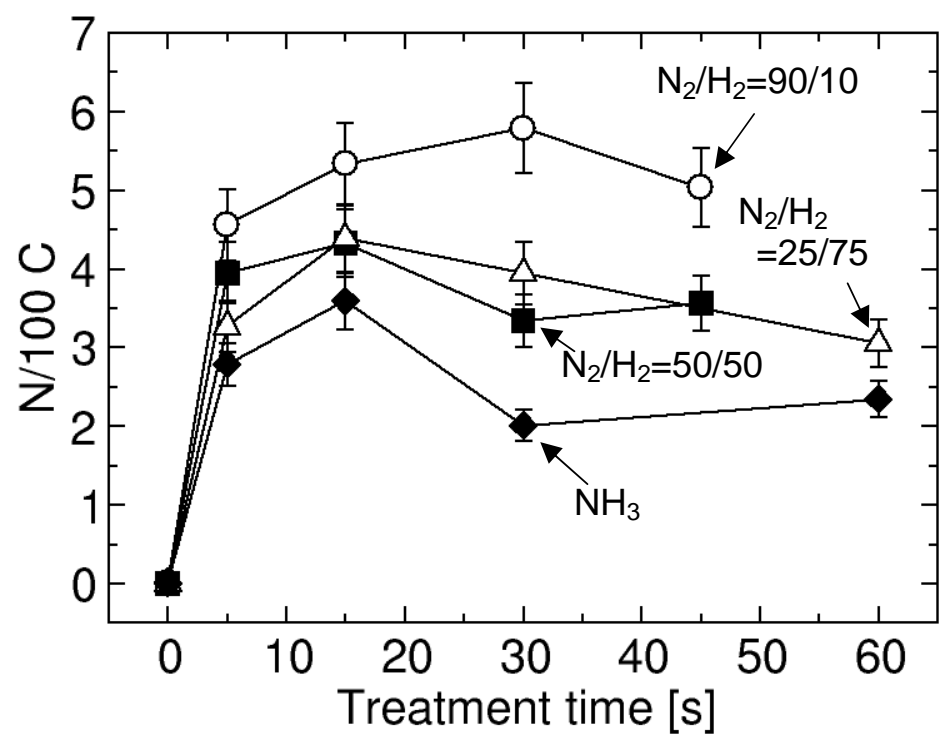

Figure 7. 


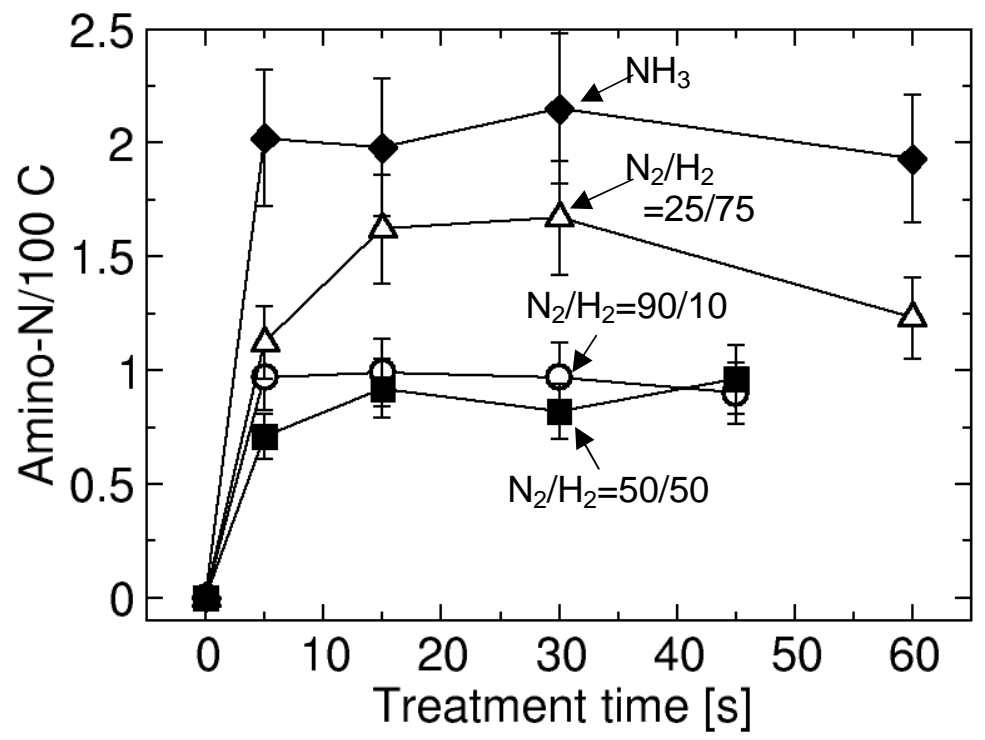

Figure 8. 


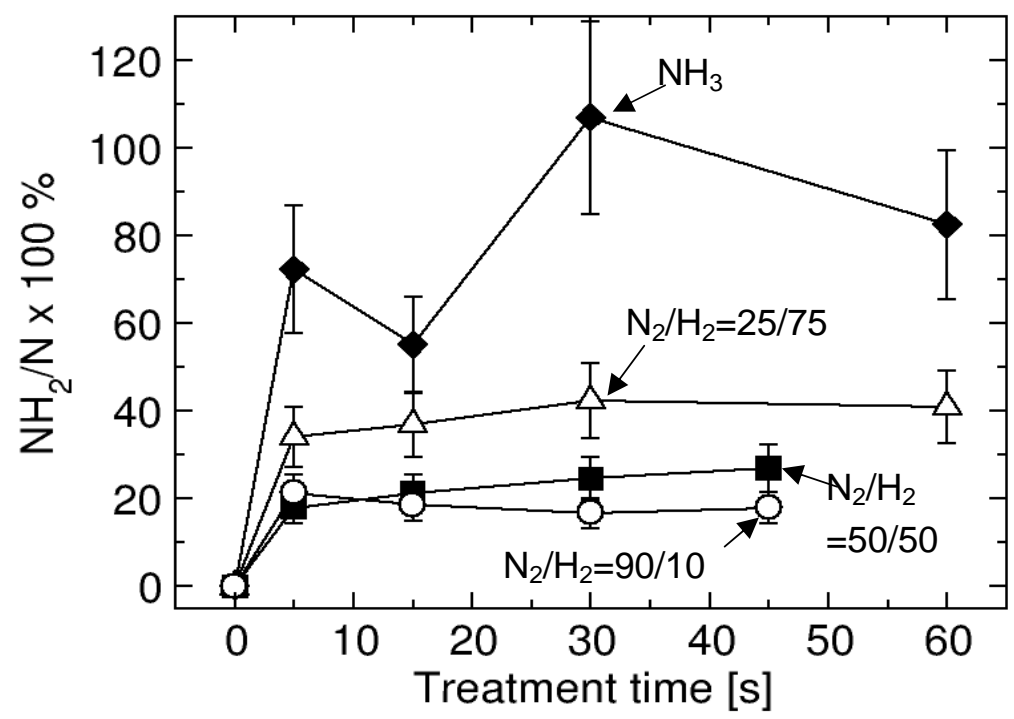

Figure 9. 